\title{
Pleie- og omsorgspersonell i akuttmedisinske team
}

\author{
Sammendrag \\ Bakgrunn. Fylkene Troms og Finnmark \\ er preget av store områder med spredt \\ bosetting og til dels lange responstider \\ for ambulanse og lege. Vi ønsket å kart- \\ legge i hvilken grad den kommunale \\ akuttberedskapen i disse fylkene bru- \\ ker ansatte fra den kommunale pleie- \\ og omsorgstjenesten, og om disse inn- \\ går i lokale akuttmedisinske team. \\ Materiale og metode. Høsten 2008 \\ sendte vi ut et spørreskjema til \\ kommunelegene og pleie- og \\ omsorgslederne i alle 44 kommuner \\ i Troms og Finnmark. Svarene ble \\ analysert manuelt.
}

Resultater. Vi mottok svar fra $41 \mathrm{kom}-$ muner. 134 av disse trener ansatte fra den kommunale pleie- og omsorgstjenesten på akuttmedisinske prosedyrer. Innholdet i øvelsene overstiger i stor grad et vanlig førstehjelpskurs. I tre av fire kommuner deltar ikke ambulansepersonell i samtrening. I 31 kommuner blir pleiepersonalet kontaktet direkte av innbyggerne ved akutt sykdom, og i kun ti av kommunene er pleie- og hjelpepersonalet organisert sammen med lege og ambulanse i lokale akuttmedisinske team.

Fortolkning. I distriktene er ansatte i pleie- og omsorgstjenesten en ressurs i akuttmedisinsk sammenheng. Potensialet i denne yrkesgruppen kan utnyttes bedre og være et viktig supplement ved akuttmedisinske hendelser. Tverrfaglig akuttmedisinsk samhandling krever tydelig organisatorisk og økonomisk struktur, lokal forankring og ledelse.

\author{
Frank Hilpüsch \\ frank.hilpusch@hlink.no \\ Petra Parschat \\ Bjarkøy legekontor \\ 9426 Bjarkøy \\ Sissel Fenes \\ Bjarkøy sykehjem \\ Ivar J. Aaraas \\ Nasjonalt senter for distriktsmedisin \\ Institutt for samfunnsmedisin \\ Universitetet i Tromsø \\ Mads Gilbert \\ Akuttmedisinsk klinikk \\ Universitetssykehuset Nord-Norge \\ og \\ Det helsevitenskapelige fakultet \\ Universitetet i Tromsø
}

Den kommunale helsetjenesten har et lovpålagt ansvar for det akuttmedisinske tilbudet til sine innbyggere. I distriktene er den lokale akuttberedskapen et avgjørende ledd i den akuttmedisinske tiltakskjeden. Beredskapen i kommunene er fastlagt i statlige retningslinjer, men preges av store lokale variasjoner (1-3). Tilbudene endres stadig som følge av større legevaktdistrikter, organisatoriske endringer i ambulanse- og spesialisthelsetjenesten, krav om økt samhandling, nytt medisinsk utstyr og nye behandlingsmuligheter (4-8). Dette skjerper også kompetansekravene til helsearbeiderne (9).

I Bjarkøy kommune i Troms har vi de siste ni årene utviklet en ny modell for kommunalt forankret akuttmedisinsk beredskap. Hovedelementene er enkle og bygger på systematisk, intern opplæring og bruk av de ressursene som allerede finnes i kommunen (ramme 1). Kommunen er en av Norges minste. De 482 innbyggerne bor på fire øyer, alle uten fastlandsforbindelse, med lang transporttid til nærmeste sykehus og legevaktsentral. Kommunen har ikke hatt egen ambulansetjeneste frem til 2006. Akuttberedskapen har i perioder vært utilfredsstillende og innbyggerne i Bjarkøy kommune har derfor ofte tatt direkte kontakt med sykehjemmet ved akutt alvorlig sykdom.

I forbindelse med innføringen av desentralisert prehospital trombolytisk behandling i Helse Nord i 2000 fikk alle kommunene i Troms og Finnmark, og de fleste kommunene i Nordland, nytt standardisert akuttmedisinsk utstyr fra Helse Nord. Med utstyret fulgte en egen opplæringspakke i avansert hjerte-lunge-redning (A-HLR) og tidlig behandling av akutt hjerteinfarkt, med blant annet prehospital trombolytisk behandling (PHT) $(4,5)$.

Samme år valgte vi å organisere det lokale helsepersonellet i Bjarkøy kommune i en egen «akuttgruppe» rundt denne utstyrs- og opplæringspakken, med sykepleiere fra pleieog omsorgstjenesten, legesekretær, helsesøster og kommuneleger. Gruppen gjennomfører intern opplæring og praktiske fellesøvelser to timer hver sjette uke (fig 1). Fra 2006 har også lokalt ambulansepersonell deltatt i øvelsene.

Med utgangspunkt $i$ vår modell ville vi finne ut hvordan det akuttmedisinske tilbudet er organisert $\mathrm{i}$ andre kommuner i Troms og Finnmark og kartlegge hvordan ansatte i kommunale pleie- og omsorgstjenester brukes i akuttmedisinske situasjoner. Vi ville dessuten se på om det er andre modeller for organisering av kommunale akuttmedisinske tilbud enn den tradisjonelle samhandlingen mellom akuttmedisinsk kommunikasjonssentral (AMK), ambulanse og lege.

\section{Materiale og metode}

$\mathrm{Vi}$ sendte et spørreskjema til samtlige 44 kommuner i Troms og Finnmark i oktober 2008. Samme skjema ble sendt til leder for pleie- og omsorgstjenesten og til kommuneoverlegen, ettersom spørsmålene burde berøre disse etatene i like stor grad. Skjemaet ble sendt både i papirversjon og som en nettbasert lenke. Vi gjennomgikk svarene manuelt, fordi det nettbaserte skjemaet ikke tillot differensiering mellom pleie- og omsorgstjeneste og legetjeneste. Når det var motstridende svar fra legetjenesten og pleie- og omsorgstjenesten, kontaktet vi kommunene direkte for å få mest mulig korrekte opplysninger.

Spørreskjemaet inneholdt 18 spørsmål om respondenten, om lokal akuttmedisinsk opplæring og om kommunalt akuttmedisinsk tilbud. Respondenten kunne gi utfyllende kom-

\section{Hovedbudskap}

- Ansatte i kommunal pleie- og omsorgstjeneste trener i stor grad på akuttmedisinske prosedyrer

- Yrkesgruppen er en for lite brukt ressurs i akuttmedisinsk sammenheng i kommuner med lang avstand til legevakt eller ambulanse

- Lokale tverrfaglige akutteam er et verdifullt supplement i distriktskommuner 
mentarer i fritekst. Alle som ikke hadde svart innen fristen, mottok en purring per e-post.

Kommunene som svarte at de brukte ansatte fra pleie- og omsorgstjenesten i sine akutteam, fikk i mars 2009 tilsendt seks nye spørsmål om teamets oppgaver og organisering. Spørsmålene ble besvart i fritekst. Kommuner som ikke svarte innen fristen, ble purret skriftlig og per telefon.

\section{Resultater}

I alt 41 av 44 kommuner (93\%) deltok i undersøkelsen. Vi mottok 57 av 88 (65\%) utfylte spørreskjemaer, hvorav 24 var fra lege og 33 var fra pleie- og omsorgstjenesten. Representantene for pleie- og omsorgstjenesten hadde lengre ansiennitet enn legene, og en firedel av legene som svarte hadde ansiennitet under ett år. I 16 kommuner, der vi mottok svar fra begge etater, hadde legetjenesten og pleie- og omsorgstjenesten til dels ulike svar.

\section{$\emptyset$ velser}

I 34 av 41 kommuner ( $83 \%$ ) øver ansatte i pleie- og omsorgstjenesten på mestring av akuttmedisinske tilstander. Tabell 1 viser hvilke yrkesgrupper som deltar på øvelsene. Det er store forskjeller mellom kommunene, men sykepleiere deltar i alle kommunene som har øvelser.

Ansatte i pleie- og omsorgstjenesten deltar

\section{Ramme 1}

\section{Bjarkøymodellen}

- Lokal akuttgruppe med sykepleiere, legesekretær, helsesøster, ambulansepersonell og kommuneleger

- Strukturert intern teamtrening og opplæring gjennom praktiske fellesøvelser to timer hver 6. uke

Gruppens medlemmer har formell delegasjon til avansert hjerte-lungeredning og bruk av defibrillator (Zoll-M), opptak og sending av 12-avledningsEKG, venekanylering og medisinering, og prehospital trombolytisk behandling

- Akuttmedisinsk utstyr og trombolysesett er utplassert på sykehjemmet (i tillegg til ambulansens utstyr)

- Varsling av akuttgruppen skjer via sykehjemmet, enten fra AMK eller fra pasient

Sykepleier i bakvakt på sykehjemmet har delegasjon til selvstendig behandling og kan ved behov rykke ut

- Akuttgruppens personell er i ordinær tjeneste og inngår i sin vanlige vaktturnus

Sykepleiere, helsesøster og legesekretær mottar et beskjedent årlig tilskudd fra kommunen for deltakelse i akuttgruppen

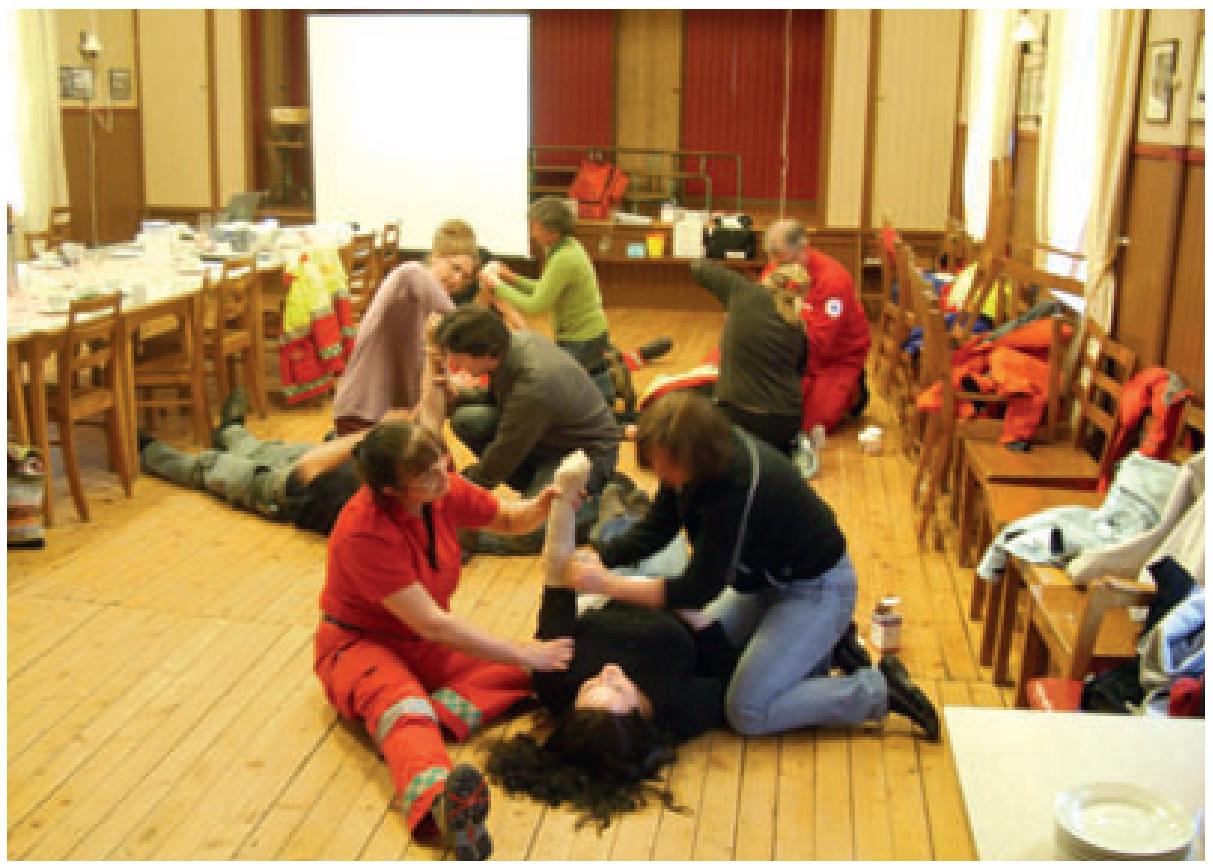

En typisk øvelse i Bjarkøy kommunes akutteam. Pleiepersonalet, ambulansepersonell og legene løser varierende akuttmedisinske oppgaver i tverrfaglige team. Her øves blødningskontroll. Foto Mads Gilbert

på akuttøvelser minst én gang $\mathrm{i}$ året. I halvparten av kommunene (20/41) øves det to eller flere ganger $\mathrm{i}$ året. Øvelsene varer gjennomsnittlig to timer, med variasjon fra én time til en hel dag. I tre av fire kommuner deltar ikke det lokale ambulansepersonellet $\mathrm{i}$ disse fellesøvelsene. Innholdet i de kommunale øvelsene fremgår i tabell 2.

\section{Akuttmedisinsk tilbud i kommunene}

Det akuttmedisinske tilbudet ble beskrevet som godt eller tilfredsstillende i 27 kommuner, mens 14 kommuner svarte at tilbudet kunne vært bedre. I 27 kommuner finnes det tettsteder som har mer enn 20 minutters utrykningstid fra nærmeste ambulansestasjon eller legevaktsentral. I 15 av de 27 kommunene eksisterer det et døgnkontinuerlig tilbud fra pleie- og omsorgstjenesten i slike tettsteder.

I 31 av 41 kommuner tar innbyggerne direkte kontakt med pleie- og omsorgstjenesten ved akutt alvorlig sykdom. I 11 av 24 kommuner med svar fra legetjenesten er legene ikke kjent med denne lokale kontaktmåten.

\section{Lokale akuttmedisinske team}

Ti kommuner besvarte tilleggsspørsmål om akuttmedisinske team der ansatte fra pleieog omsorgstjenesten inngår. Sju av kommunene ligger i Finnmark. I ni av kommunene er akuttberedskapen organisert $i$ en etablert vaktordning for pleie- og omsorgstjenesten. Tilbudet er samlokalisert med sykehjem i sju av kommunene, der seks også har sykestuefunksjon. Alle deltakerne trener avansert hjerte-lunge-redning og i de fleste kommunene trener både legene, ambulansepersonellet og sykepleierne på bruk av hjertestarter og opptak med sending av 12-avlednings-EKG. I tillegg til legene og ambulansepersonellet deltar også sykepleie- re ved trombolytisk behandling ved akutt hjerteinfarkt i tre kommuner.

Det å samle alle deltakerne til øvelser, samordne øvelsene mellom forskjellige fagetater, innlære standardalgoritmer, bruke og mestre avansert utstyr, innarbeide gode varslingsrutiner og ha tilstrekkelige økonomiske rammer ble angitt som de viktigste utfordringene $\mathrm{i}$ arbeidet med å organisere og drifte kommunale akuttmedisinske team med pleieog omsorgstjenesten. Bjarkøy er eneste kommune der alle kommunalt ansatte sykepleiere har delegasjon til primærbehandling av akutte brystsmerter og hjerteinfarkt, inkludert prehospital trombolytisk behandling.

\section{Diskusjon}

Ved å henvende oss både til kommuneoverleger og ledere for pleie- og omsorgstjenesten fikk vi høy svarprosent, med informasjon fra $93 \%$ av kommunene. Selv om adekvat håndtering av akuttmedisinske situasjoner $\mathrm{i}$ mange kommuner berører både legetjenesten og pleie- og omsorgstjenesten, synes disse etatene ikke alltid å være klar over felles oppgaver og ansvar. Med samhandlingsreformens fokus på økt intrakommunalt samarbeid, tyder våre funn på et klart potensial for bedre kommunikasjon og samhandling mellom kommunale helse- og omsorgsetater.

I mange nordnorske kommuner trenes det på et mangfold av prosedyrer i ulike gruppesammensetninger. Dette tyder på at helsepersonell i kommunene tar ansvar for lokal kompetanseheving og beredskap, men mangler til dels felles målsetning, retningslinjer og ledelse.

I krigsrammede lokalsamfunn med lang responstid for ambulanse og lange avstander til sykehus har systematisk trening av lokale akutteam basert på det helsepersonellet som alt finnes i lokalsamfunnet, gitt til dels dra- 
matiske forbedringer i overlevelse i tidskritiske akuttsituasjoner $(10,11)$. Vi tror Norge kan lære av slike erfaringer, også i fredstid.

\section{Pleiepersonell trener akuttmedisin}

Sykepleiere og hjelpepleiere antas å ha gode kunnskaper i basal hjerte- lunge-redning gjennom utdanningen. Våre funn tyder på at de samme yrkesgruppene er opptatt av å vedlikeholde og utvide kunnskaper og ferdigheter gjennom regelmessige øvelser. Prosedyrene de øver på er relativt omfattende og til dels langt mer avanserte enn ved tradisjonelle førstehjelpskurs. Der det øves, planlegges og gjennomføres dette i lokal regi. Spesialisthelsetjenesten og det regionale helseforetaket nevnes ikke spontant av noen kommuner, heller ikke av de ti kommunene som har egne akutteam. Dette kan tyde på at annenlinjetjenesten i liten grad er involvert $i$ den lokale akuttmedisinske opplæringen av pleie- og omsorgspersonalet. Tatt i betraktning den kompetansen som finnes - særlig i ambulansetjenesten - og den veiledningsfunksjonen spesialisthelsetjenesten skal ivareta, er det et klart potensial for å bedre gjensidig kunnskap og samhandling mellom disse nivåene i helsetjenesten (7).

Ambulansetjenesten er overraskende lite representert og deltar bare $\mathrm{i}$ en firedel av kommunene som driver lokale akuttøvelser. Dette kan skyldes at ambulansetjenesten er organisert i og har fagmedisinsk ledelse i spesialisthelsetjenesten og øver selvstendig eller bare sammen med legetjenesten i kommunen. Vi tror gevinsten i samtrening med denne faggruppen er stor.

Ulike kurstilbud i akuttmedisin fra stiftelser og organisasjoner, som for eksempel Norsk Luftambulanse og Norges Røde Kors, er ut- bredt i Kommune-Norge. Dette kan være en forklaring på at enkelte respondenter oppgir årlige heldagskurs som eneste øvingstilbud.

\section{Lokalbefolkningen}

\section{kontakter pleiepersonalet}

Flere «utkantstrøk» har døgnkontinuerlige tilbud fra den lokale pleie- og omsorgstjenesten, der personalet er en potensiell ressurs med betydelig akuttmedisinsk kompetanse.

I distriktene nyter denne stabile yrkesgruppen stor respekt $\mathrm{i}$ befolkningen og har god lokalkunnskap. I Bjarkøy kommune har innbyggerne tradisjonelt kontaktet sykehjemmet og sykepleierne direkte ved akutt sykdom, særlig i perioder med dårlig legedekning. Funnene tyder på at det samme handlingsmønsteret er utbredt også i andre kommuner i Troms og Finnmark.

Det er viktig å erkjenne at ansatte i pleieog omsorgstjenesten faktisk kontaktes direkte ved akutt alvorlig sykdom, selv om type kontakt og type råd ikke fremgår av denne studien. Denne «trafikkveien» synes å være mindre kjent for legetjenesten. Pleiepersonalets gode pasientkontakt og lokalkunnskap er et viktig bidrag til at personer i terminalfasen får dø i hjemkommunen (hjemme eller i sykehjem), uten at situasjonen håndteres som en akuttmedisinsk nødsituasjon som ender med uheldig sykehusinnleggelse (12).

\section{Tilfredshet}

På bakgrunn av regionens krevende geografi og spredte bosetting er vi overrasket over at helsepersonell i to av tre kommuner mente det akuttmedisinske tilbudet var bra eller tilfredsstillende for de fleste innbyggerne $\mathrm{i}$ kommunen, mens bare én av tre mente tilbudet kunne vært bedre. Vi tror tilfredsheten

Tabell 1 Yrkesgruppenes deltakelse i akuttmedisinske øvelser i 34 kommuner i Troms og Finnmark

\begin{tabular}{|c|c|c|c|c|c|c|c|c|}
\hline & $\begin{array}{l}\text { Syke- } \\
\text { pleier }\end{array}$ & Lege & $\begin{array}{l}\text { Hjelpe- } \\
\text { pleier }\end{array}$ & $\begin{array}{l}\text { Ambu- } \\
\text { lanse }\end{array}$ & $\begin{array}{l}\text { Ufag- } \\
\text { lært }\end{array}$ & $\begin{array}{l}\text { Helse- } \\
\text { søster }\end{array}$ & $\begin{array}{c}\text { Kontor- } \\
\text { ansatt }\end{array}$ & $\begin{array}{l}\text { Andre } \\
\text { etater }\end{array}$ \\
\hline $\begin{array}{l}\text { Antall kommuner der } \\
\text { yrkesgruppen deltar (\%) }\end{array}$ & $34(100)$ & $26(76)$ & $25(74)$ & $8(24)$ & $8(24)$ & 3 (9) & $4(12)$ & 5 (15) \\
\hline
\end{tabular}

Tabell 2 Akuttmedisinske prosedyrer som trenes i kommunale øvelser ( $n=34$ )

Prosedyre

Basal hjerte-lunge-redning (HLR)

Antall kommuner (\%)

Avansert hjerte-lunge-redning (A-HLR)

33 (97)

Defibrillering med halvautomatisk hjertestarter (D-HLR)

$22(65)$

Bruk av Norsk indeks for medisinsk nødhjelp

$25(74)$

Gjennomføring av prehospital trombolyse (PHT)

$9(26)$

Venekanylering

$12(35)$

$14(41)$

$14(41)$

$13(38)$

Kontroll av ytre blødning

$18(53)$ delvis kan forklares med de senere årenes betydelige utbygging og faglige styrkning av ambulansetilbudet fra spesialisthelsetjenesten $(9,13)$. En annen forklaring kan være at det ikke forventes samme tilbud i distriktene som i byene. Det er fortsatt betydelige forskjeller i prehospitale responstider mellom by- og landkommuner (14).

\section{Akutteam og samhandling}

Ti kommuner har utvidet sitt lokale akuttmedisinske tilbud gjennom aktiv bruk av ansatte fra pleie- og omsorgstjenesten i akuttberedskapen, men de lokale akuttmedisinske teamene har variert oppbygning. Som oftest fungerer sykepleier som en forsterkning ved mottak i sykestuen eller på legevakten, men deltar sjelden i utrykninger. Flere kommuner, særlig i Finnmark, har samlokalisert akuttmedisinsk tilbud og sykestuefunksjon. Sykestuene har en lang tradisjon i DistriktsNorge og representerer velfungerende intrakommunal samhandling i det akuttmedisinske tilbudet (15). Som i Bjarkøy ser flere kommuner fordelen av å bruke en bredest mulig fagkompetanse $\mathrm{i}$ akuttmedisinske situasjoner. Utfordringene som de lokale akuttteamene møter, sammenfaller godt med utfordringer vi har møtt de siste ni år i utviklingen av vårt eget akutteam.

Basert blant annet på det akuttmedisinske utstyret og opplæringspakken Helse Nord ga kommunene ved oppstart av prehospital trombolytisk behandling i 2000 burde de materielle forutsetningene være likeverdige de fleste steder i Nord-Norge. Vi har likevel ikke funnet andre modeller der ansatte fra pleie- og omsorgstjenesten er organisert i lokale akutteam og øver med legene og ambulansepersonalet i samme grad som i Bjarkøy kommune. En slik modell krever god organisering og logistikk, men uten entusiasme og glede ved lokal samhandling hjelper det ikke med utstyr alene.

\section{Konklusjon}

Ansatte i den kommunale pleie- og omsorgstjenesten er en viktig ressurs ved akuttmedisinske hendelser i mange distrikter. Gjennom kompetanse og lokal tilgjengelighet $\mathrm{i}$ etablerte vaktordninger representerer disse et stort og til dels ubrukt potensial for en bedre akuttmedisinsk beredskap i form av lokale, tverrfaglige akutteam. Dette forutsetter imidlertid regelmessig og systematisk trening, etablering av varslingsrutiner, kvalitetssikring og nødvendig avlønning. Deltakelsen kan ikke baseres på frivillighet, men krever forankring i kommunalt planverk, tydelig ledelse og samarbeid med spesialisthelsetjenesten, spesielt ambulansetjenestene. Økt fokus på lokal tverrfaglig samhandling bør kunne resultere i stimuleringstiltak for distriktskommunene både i form av nye retningslinjer, veiledere og nødvendig økonomisk støtte.

Oppgitte interessekonflikter: Ingen 


\section{Litteratur}

1. Nieber T, Hansen EH, Bondevik GT et al. Organisering av legevakt. Tidsskr Nor Lægeforen 2007; 127: $1335-8$

2. Lov om helsepersonell av 2.7.1999 nr. 64.

3. ... er hjelpa nærmast! Forslag til Nasjonal handlingsplan for legevakt. Rapport nr. 1/2009. Bergen: Nasjonalt kompetansesenter for legevaktmedisin, 2009

4. Steigen TK, Wiseth R, Nordrehaug JE. Trombolytisk behandling. Tidsskr Nor Lægeforen 2004; 124 $640-3$.

5. Aune E, Steen-Hansen JE, Hjelmesæth J et al. Prehospital diagnostikk og behandling av akut hjerteinfarkt i Vestfold. Tidsskr Nor Lægeforen 2004: 124: 3058-60.

6. St meld. nr. 47 (2008-09). Samhandlingsreformen Rett behandling - på rett sted - til rett tid.

7. Helse- og omsorgsdepartementet. Lov om spesialisthelsetjenesten m.m. (spesialisthelsetjenestelo- ven]. www Lovdata no/all/hl-19990702-061 html, (1.3.2010).

8. Bjøru H, Langfeldt E, Løvland A et al. Streptokinasebehandling i Nordkapp. Tidsskr Nor Lægeforen 1998; 118: 2632-3.

9. Forskrift om krav til akuttmedisinske tjenester utenfor sykehus av 18.3.2005 nr. 252.

10. Husum H, Gilbert M, Wisborg T et al. Rural prehospital trauma systems improve trauma outcome in low-income countries: a prospective study from North Iraq and Cambodia. J Trauma 2003; 54: $1188-96$.

11. Husum H, Gilbert M, Wisborg T. Save Lives Save Limbs. Penang, Malaysia: Third World Network. 2000.

12. Aaraas I, Langfeldt E, Ersdal G et al. Sykestuemodellen, nøkkel til bedre samhandling i helsetjenesten - la sykestuene leve! Tidsskr Nor Lægeforen 2000; 120: 702-5.
13. St meld nr 43 (1999-2000) Om akuttmedisinsk beredskap.

14. Folkestad EH, Gilbert M, Steen-Hansen JE. Når det haster - prehospitale responstider i Vestfold og Troms i 2001. Tidsskr Nor Lægeforen 2004; 124: $324-8$

15. Aaraas I, Melbye H, Eriksen BO et al. Is the genera practitioner hospital a potential «patient trap»? A panel study of emergency cases transferred to higher level hospitals. Scand J Prim Health Care 1998; 16: 76-80.

Mottatt 10.3. 2010, første revisjon innsendt 8.8. 2010, godkjent 9.9. 2010. Medisinsk redaktør Are Brean. 